\title{
Pilzfinder.at
}

\section{Diversity and distribution of fungi in Austria. Let us search for fungi, take pictures, document them and thereby contribute to biodiversity research}

\author{
Irmgard Krisai-Greilhuber ${ }^{a, 1}$ \\ ${ }^{a}$ Austrian Mycological Society, Dept. of Botany, University of Vienna, \\ Rennweg 14, 1030 Wien, Austria \\ E-mail: irmgard.greilhuber@univie.ac.at
}

\begin{abstract}
Pilzfinder.at is a citizen science project of the Austrian Mycological Society (ÖMG) in

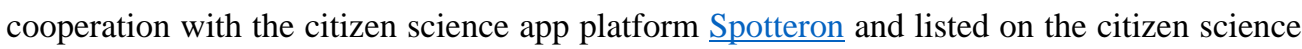
platform "Österreich forscht". Citizen scientists document fungal observations by photography supplemented with notes on ecology. Nearly 2000 observations from 50 citizen scientists were produced in 2019, including rare species observations. Engagement of citizen scientists significantly improves research regarding to distribution and ecology of fungi in Austria and increases the reliability of forecasts for Red Lists and for fungal threats globally.
\end{abstract}




\section{Introduction}

Pilzfinder.at is a citizen science project of the Austrian Mycological Society (ÖMG) in cooperation with the citizen science software platform Spotteron and listed on the platform "Österreich forscht". It is accessible via the ÖMG homepage as desktop app.

\section{Research aspects}

\subsection{Topics}

Until a few decades ago, knowledge of wild fungi was widespread. In order to preserve this knowledge, to expand it and to bring it closer to the younger generation, the desktop app Pilzfinder was programmed and is available since March 2019. As a result of global warming, in recent years the occurrence of fungi and the range of species are increasingly shifting. Data on fungi from European countries show that the time of appearance of the fruiting bodies starts earlier and ends later as a result of global warming, so that today fungi appear over a longer period of time in the course of the year [1]. The ÖMG investigates the distribution of fungi in Austria with the help of citizen scientists since years. With the active help of citizen scientists in Pilzfinder.at, changes in occurrence are now also recorded and incorporated into scientific evaluations.

\subsection{Research questions and goals}

- 1. Which fungi occur in Austria and beyond? - i.e. species survey.

-2. Where do they occur? - a contribution to the fungal mapping project.

-3. When do they grow? - knowledge of the temporal occurrence of fungi helps to record the temporal shifts in the spectrum of species due to global warming.

- 4. How often, in what quantity and at what altitude do they grow? - there are already clearly visible changes in phenology and distribution related to the different altitudes due to climate change. In the Alps many fungi are migrating upwards, because fungi react immediately to the present temperature development [2].

\section{Contributions of citizen scientists}

\subsection{How can citizen scientists do research?}

They can look out for, find, and photograph fungi outdoors. Back home they open the desktop app, search the observation site on the interactive map of Pilzfinder.at, upload the respective photos and add comments on the area (Fig. 1).

It is important to document the fungi correctly. They can best be identified with meaningful and well-focussed photos. It is helpful to have several views, namely from above, from the side, from below, and a sectional image to be able to recognize the flesh colour and any discoloration or a milky juice.

Furthermore, ecological information on the observation site is desirable as a determination aid. Whether the fungus grew in the deciduous or coniferous forest, whether it was alone or in groups, or how it smells. All this information can be entered in the desktop app.

In the administration background moderators can insert identifications and changes. 


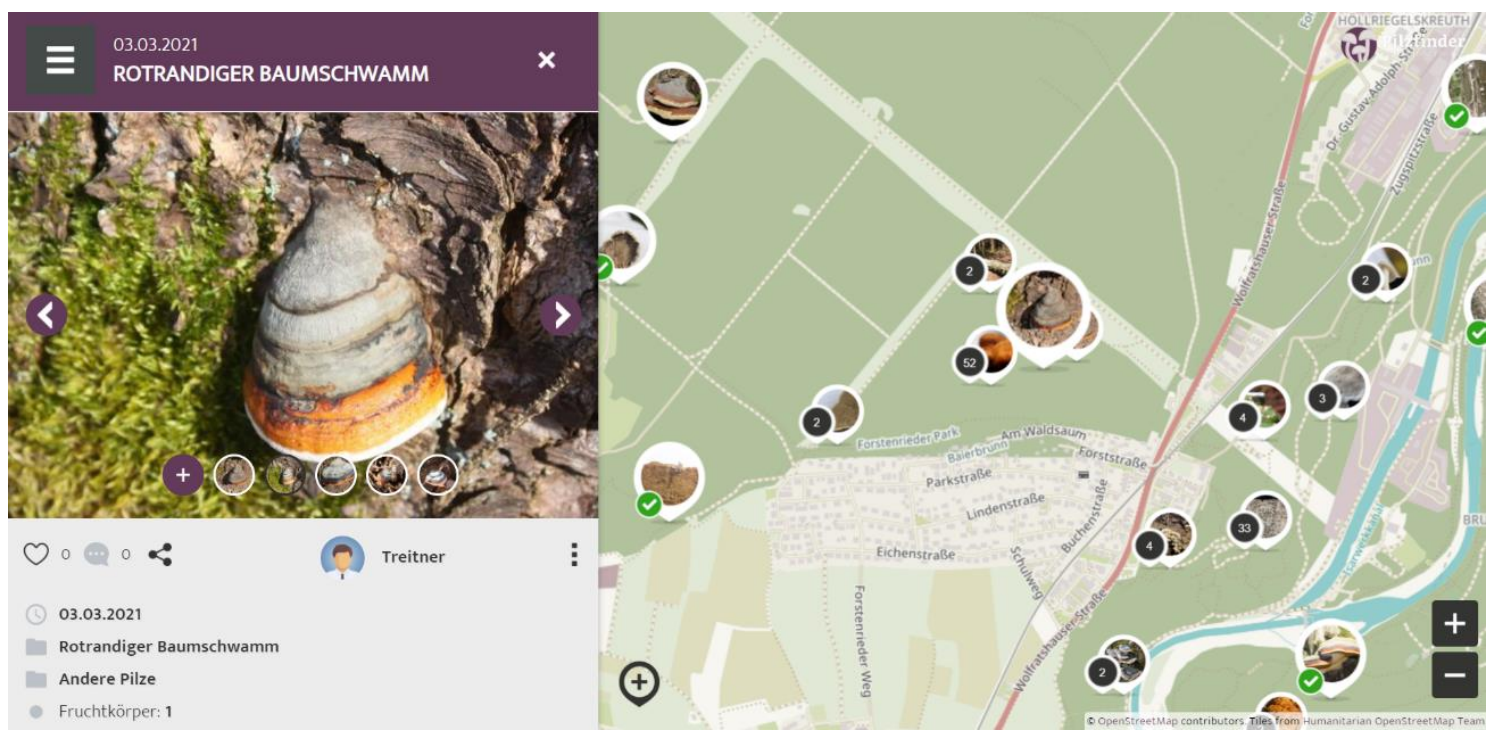

Fig 1: Fomitopsis pinicola, an example of an observation in pilzfinder.at; photo S. Treitner.

\subsection{Community}

A community function enables quick communication among citizen scientists and feedback by admins. Details of observations can be asked and identifications discussed.

\subsection{What happens to the contributions of citizen scientists?}

The photos are all online in Pilzfinder.at. If possible, the fungi are determined on sight to species level by experts. The determined fungi are included in the database of the ÖMG and finally uploaded to GBIF via the ÖMG database. They are available for evaluations, flow into research and can be used for scientific publications.

The citizen scientists get to know the species of their observations and those of other citizen scientists and expand their knowledge. They see where and when fungi grow and can do further research themselves.

\section{History of the ÖMG database}

Fungal distribution data collection by the ÖMG began in 1980 with a project by the Vienna municipality to map Vienna's fungi; the data was entered into a first database 1981-1990. Subsequently, the idea of an Austria-wide database arose and was implemented in 2005. In 2009 it was decided to go online open access. Presently, distribution maps of individual species, illustrations, and other information, such as altitude and substrates, can be retrieved from the ÖMG database.

\section{Results}

\subsection{The first year}

Since the beginning of Pilzfinder.at on March 16 until December 31, 2019, 3062 photos were uploaded by 56 citizen scientists resulting in 1991 species observations. $40-100 \%$ of the observations from a citizen scientist could be used for the fungal distribution mapping. The 
average was $76 \%$. The number of observations per citizen scientist fluctuated from 1 to 354 . Only 17 observations were incorrectly located, e.g. offshore in the sea, tests or double spots.
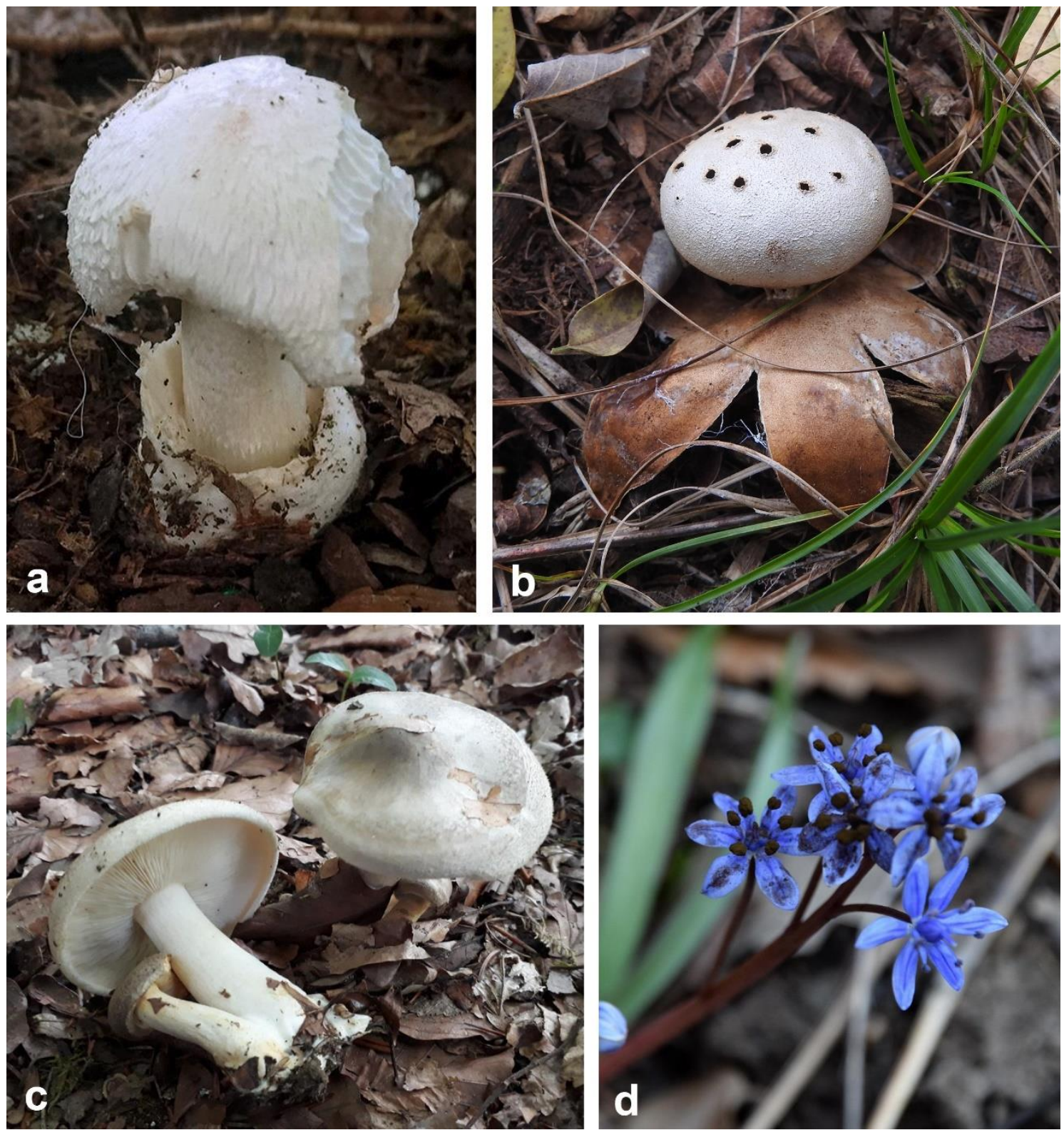

Fig 2: Important observations in Pilzfinder.at made by citizen scientists. a Volvariella surrecta, rare species, photo M. Koncilja; b Myriostoma coliforme, rare species, photo B. Tobler; c Pogonoloma spinulosum, first find for Austria, photo V. Scherer; d Antherospora vindobonensis, fourth find for Austria, photo M. Sabor.

\subsection{Observations of rare species}

In addition to common fungal species, there were also sensational finds, such as the aromatic meadow hat (Pogonoloma spinulosum), the piggyback rosegill (Volvariella surrecta) and the saltshaker earthstar (Myriostoma coliforme) (Fig. 2). 
Further remarkable observations are those of the bluestar anther smut fungus (Antherospora vindobonensis) being only the fourth and fifth observation for Austria.

In the blog on the Spotteron overview platform there is an example of an important observation made by a citizen scientist. The fungi were photographed by him, uploaded and subsequently collected in the field and identified by experts as Psathyrella typhae. This species is in the Red List of Endangered Fungi in Austria as threatened with extinction [3]. The observation found also its way to Twitter. It was the first confirmed identification for Vienna. In addition, it was helpful that the citizen scientist included a scale bar in his photos.

In 2020, a species of the tinder fungus aggregate, namely Fomes inzengae, was detected for the first time in Austria. It is supposed to have its main distribution in the Mediterranean area on oaks. Meanwhile, the identification has been also genetically verified.

\subsection{Geographical coverage and success rate}

The observations for the Pilzfinder.at come from all over Austria, from Germany, Poland, Croatia, England, Switzerland, Belgium and Madagascar. Only 366 observations of the first year could not be clearly identified. Although many fungi can only be identified microscopically, the start of Pilzfinder.at with 1625 new observations was successful.

A first glance at 2020 shows that more than 11700 photos were uploaded by the end of October. In addition to observations for Austria by Austrian citizen scientists, there were also many from Munich and Antwerp uploaded by citizen scientists from other European countries showing that Pilzfinder.at is more visible internationally and citizen scientists from other countries participate in the project.

\subsection{An example of media presence}

There is a blog post about the project on "Österreich forscht" with an interview conducted with two citizen scientists. It also indicates that Pilzfinder.at creates a win-win situation for everyone involved, because citizen scientists find recreation in nature and get to know fungi, and research institutions receive data distributed across Austria and beyond, which they could not collect themselves to this extent.

\section{Conclusions}

Participation of citizen scientists in pilzfinder.at significantly improves research about the distribution of fungi occurring in Austria and the recording of changes in occurrence and species composition over time. The observations increase the reliability of forecasts, for example for the Red List of fungi in Austria or for fungal threat globally.

Our thanks go to Philipp J. Hummer from Spotteron for continuous support.

\section{References}

[1] J. Diez, H. Kauserud, C. Andrew, E. Heegaard, I. Krisai-Greilhuber, B. Senn-Irlet, K. Høiland, S. Egli and U. Büntgen, Altitudinal upwards shifts in fungal fruiting in the Alps. Proc. Royal Soc. B, Biol. Sci. 287 (issue 2019). https://doi.org/10.1098/rspb.2019.2348B 
[2] C. Andrew, E. Heegaard, C. Høiland, B. Senn-Irlet, T.W. Kuyper, I. Krisai-Greilhuber, P.M. Kirk, J. Heilmann-Clausen, A.C. Gange, S. Egli, C. Bässler, U. Büntgen, L. Boddy and H. Kauserud, Explaining European fungal fruiting phenology with climate variability. Ecology 99(6): 1306-1315 (issue 2018). https://doi.org/10.1002/ecy.2237

[3] W. Dämon and I. Krisai-Greilhuber, I., 2017: Die Pilze Österreichs. Verzeichnis und Rote Liste 2016. Teil Makromyzeten. - Wien: Österreichische Mykologische Gesellschaft. 